\title{
The Influence of Rice Straw on the Physical and Mechanical Properties of Banco, an Adobe Reinforced with Rice Straw
}

\author{
Clément Adéoumi Labintan, Christian Enagnon Adadja, Mohamed Gibigaye, \\ Hamid Zahrouni, Mahdia Hattab
}

\begin{abstract}
Making adobes with the best mechanical properties for the construction of earthen housings is the overall goal of this work. Specifically, we study the influence of rice straw on the physical and mechanical properties of these adobes. The physical and mechanical properties (compressive and flexural strength) of adobes (mixture of sandy clay and rice straw) have been studied with different proportions of straw in the mixture. It is a question of determining the quantity of stalks of rice straw making it possible to optimize the mechanical performances of the composite. Various compositions have been considered with mass concentrations of rice straw ranging from 0 to $40 \%$ relative to the volume of clay sand to make $4 \times 4 \times 16 \mathrm{~cm}$ prismatic specimens. The results obtained during physical and mechanical tests were presented in the form of a graph. The analysis of these data shows that the optimal addition of rice straw in the clay matrix is $25 \%$ for a better compromise between the compressive and tensile strengths. The improvement of the physical and mechanical properties of adobes is related to the good adhesion between the rice straw and the clay matrix, to the high tensile strength of the rice straw and finally to a good distribution of cracks in the composites.
\end{abstract}

Keywords: Banco, durable material, Clayey sand, Rice straw fibres, Physical and mechanical characteristics.

\section{INTRODUCTION}

Earth is probably the oldest building material. Available everywhere in the world, it has accompanied the evolution of Man in his habitat on the five continents [1]. Each region of the world has developed its own earthen architecture according to its needs, knowledge and his creativity. The patterns of earth construction were influenced by the geographical location and the usual cultures. So many construction modes exist, rammed earth, cob, adobe (banco

Revised Manuscript Received on December 30, 2019.

* Correspondence Author

Clement Labintan*, Laboratory of Energetics and Applied Mechanics, University of Abomey-Calavi, Cotonou, Benin.

Christian Adadja, Laboratory of Microstructure Studies and Mechanics of Materials, University of Lorraine, Metz, France.

Mohamed Gibigaye, Laboratory of Energetics and Applied Mechanics, University of Abomey-Calavi, Cotonou, Benin.

Hamid Zahrouni, Laboratory of Microstructure Studies and Mechanics of Materials, University of Lorraine, Metz, France.

Mahdia HATTAB, Laboratory of Microstructure Studies and Mechanics of Materials, University of Lorraine, Metz, France.

(C) The Authors. Published by Blue Eyes Intelligence Engineering and Sciences Publication (BEIESP). This is an open access article under the CC BY-NC-ND license (http://creativecommons.org/licenses/by-nc-nd/4.0/) in Africa) or compressed earth brick. Earth has been known and used in construction for many millennia [1]-[3].

Currently, it is estimated that about $30 \%$ of the world's population lives in a mud house. In fact, it is often the most easily accessible material and especially the cheapest [4].

Among these techniques, the most used in Benin, are those of adobes (brick mud molded by hand) and compressed clay brick (BTC). In addition to these two techniques, cement block bricks are used mainly in urban areas because of their mechanical strength and their resistance to water. However, cement constructions have economic and environmental disadvantages. Indeed, the cement is very expensive because the clinker is imported and the grinding of the constituents of the cement is energetic and polluting because of the emission of dust. It appears that the use of adobe (raw earth brick without the addition of cement or firing) in the construction of habitats is one of the solutions for sustainable construction for populations in low-income developing countries.

The revival of the use of land as a building material is linked to the significant reduction in environmental impact due to the use of local raw materials and simple, energy-efficient manufacturing processes [5], [6]. In addition, earth-based materials allow for better balance and thermal and acoustic control in the interior compared to conventional building materials. This is due to their performance in terms of moisture absorption/desorption, heat storage capacity (hygrothermal regulation) and sound transmission properties [6], [7].

To solve the problems related to the appearance and propagation of cracks in adobe blocks as well as the significant drying shrinkage to which this type of material is subjected, recent studies on adobes reinforced with vegetable fibres of coconut, of oil palm, sisal and organic polymers have shown that the incorporation of these reinforcements reduces cracks and improves the durability of adobes [8], [9]. Many scientific works on plant fibres for use as reinforcements in adobes have been made [10]-[13]. The fibres help to maintain cohesion and limit the shrinkage.

Improving the mechanical properties of the earth with agricultural waste fibres offers the possibility of building more robust and comfortable homes in developing countries [14]-[16]. These studies show that the stabilization of earth material significantly improves these mechanical properties, its resistance to compression [17], [18]. The addition of natural fibres and straws to the earth is part of this same logic

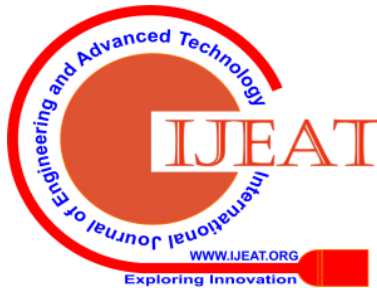


This makes them inexpensive stabilizers for clay matrix composites [19], [20]. Few reliable experimental data are available in the literature on clay soil stabilization by rice straw for banco constructions in Benin.

The objective of this work is to study the influence of rice straw used as reinforcement in the adobe blocks and to determine an optimal proportion of better mechanical resistance.

\section{MATERIALS AND METHODS}

\section{A. Materials}

The banco of the present study is a mixture of clay sand, stalks of rice straw, and water as shown in Figure 1. These constituents are those indicated in our previous work [16].

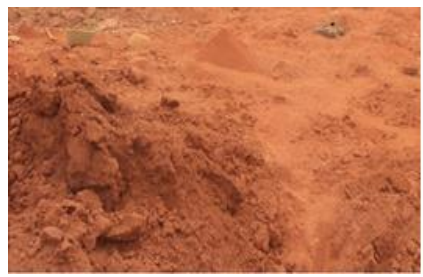

a- Sandy clay soil

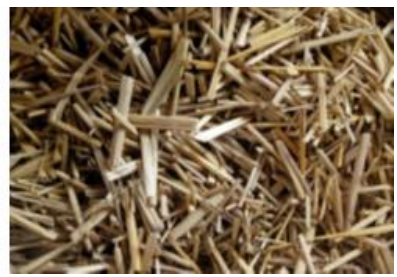

b- Pieces of stalks of rice

Figure 1: Materials used in investigations: sandy clay soil and rice straws

\section{1) Clay soil}

The clay soil used came from Abomey-Calavi ( $6{ }^{\circ} 27$ 'north latitude and $2^{\circ} 15^{\prime}$ east longitude) in southern Benin. This clay soil was chosen because of its abundance and its traditional use to produce good quality adobes by the local population.

The particle size distribution of the soil mixtures was analysed according to two techniques: the coarsest fraction ( $\geq$ $80 \mu \mathrm{m})$ was analysed by wet sieving according to standard NF P 94-056, and the finer fraction $(<80 \mu \mathrm{m})$ by pipette analysis according to standard NF P 94-057 (method based on measuring the sedimentation time of solid particles suspended in a water solution mixed with sodium hexametaphosphate as a deflocculating agent). But before, soil samples are sieved through a $5 \mathrm{~mm}$ sieve to remove large aggregates.

Physical properties of clay soil were presented below in Table 1.

Table 1: Physical properties of used clay soil.

\begin{tabular}{|c|c|c|}
\hline Property & Value & Standard \\
\hline $\begin{array}{l}\text { Content of fine elements and sand } \\
\text { after grain size analysis }\end{array}$ & & NF EN 933-1 \\
\hline - Clay soil $(<0.2 \mathrm{~mm}), \%$ & 41.77 & \\
\hline - Sand $(>0.2 \mathrm{~mm}), \%$ & 45 & \\
\hline Atterberg limits & & NF P 94-051 \\
\hline - Liquid limit (\%) & 33 & \\
\hline - Plastic limit (\%) & 17 & \\
\hline - Plasticity index (PI) & 16 & \\
\hline $\begin{array}{l}\text { Proctor test } \\
\text { - Optimum moisture content (OMC) } \\
\text { (\%) }\end{array}$ & 15.85 & NF P 94-093 \\
\hline $\begin{array}{l}\text { - Maximum dry density (MDD) } \\
\left(\mathrm{kN} / \mathrm{m}^{3}\right)\end{array}$ & 18.8 & \\
\hline Specific gravity of soil solids (G) & 2.64 & NF EN 1097-6 \\
\hline Loose bulk density & 1,23 & \\
\hline Water content (\%) & $\begin{array}{l}11.48 \\
\text { Sandy }\end{array}$ & NF P 18-555 \\
\hline Classification & $\begin{array}{l}\text { Clay } \\
\left(\mathrm{A}_{2} \mathrm{~s}\right)\end{array}$ & NF P $11-300$ \\
\hline
\end{tabular}

\section{Fibres of stalks of rice straw}

Rice straws weighing about $25 \mathrm{~kg}$ are harvested and then sun dried to constant weight. The stalks of the rice straws are separated and cut into pieces of $4 \mathrm{~cm} \pm 1$. The fibres are roughly crushed. An important characteristic of vegetable fibres is the water absorption coefficient. To determine this water absorption coefficient, the fibres were immersed in water for different times (1 minute, 5 minutes, 15 minutes, one hour, 4 hours, 24 hours and 48 hours). The average absorption value of Zinvié rice straw at 24 hours is $285 \%$.

The physical properties of rice straw fibres have been presented in Table 2.

Table 2: Physical properties of stalks of rice straws

\begin{tabular}{lll}
\hline Characteristics & Quantity & Observation \\
\hline Loose bulk density $\left(\mathrm{Mg} / \mathrm{m}^{3}\right)$ & 0,036 & NF EN 1097-3 \\
Water absorption & 252 & NF P 18-555 \\
coefficient (\%) & $1-5$ & \\
$\begin{array}{l}\text { Diameter (mm) } \\
\text { Length (mm) }\end{array}$ & $30-50$ & \\
\hline
\end{tabular}

\section{3) Specimen preparation}

We considered several formulations of the composite by varying the volume fraction of straw from 0 to $40 \%$ by volume of soil. The following percentages were considered: 0 , 20, 25, 30 and 37.

For each volume fraction of fibres of rice straw, a set of three prismatic test pieces, $40 \times 40 \times 160 \mathrm{~mm}$, were made with a mould inspired by the Guettala model [21] which together with the press formed a combination of extrusion and compression moulding. The applied stress was $1.5 \mathrm{MPa}$. The mechanical tests were made at 28 days of age of the specimens. The samples were stored under laboratory conditions until equilibrium moisture was reached (temperature $27{ }^{\circ} \mathrm{C}$ and $60 \% \mathrm{RH}$ ). Part of the tested specimens were presented in Figure 2.



Figure 2: Prismatic specimens

\section{B. Experimental methods and procedures}

Measurements of apparent density, shrinkage rate and mechanical strengths were made on the test pieces made.

Physical property tests

- The density of the specimens was determined according to BS EN 771-1. The test pieces were weighed and measured. The apparent density was determined by the ratio of the mass (in equilibrium with the relative humidity of the environment) and the volume of the specimens. The results were expressed in $\mathrm{kg} / \mathrm{m}^{3}$. 
The drying shrinkage of the test pieces is measured on both ends of each test piece and the total shrinkage is therefore the sum of the withdrawals at each end (

- Figure 3). The results were expressed in\%.

The workability of the mixture was followed during the preparation of the mixture and the manufacture of the samples. During drying, until the equilibrium with the relative humidity of the environment is reached, the appearance and development of the cracks have been followed visually.

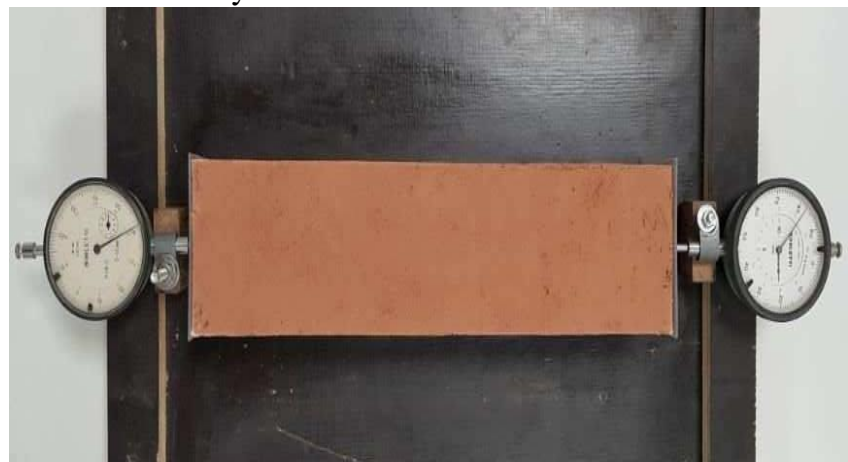

Figure 3: Measurement of drying shrinkage of a sample

\section{1) Mechanical properties tests}

The mechanical three-point bending test was performed to determine the bending tensile strength, Rf. On the two resulting halves of the test pieces after the previous test, the compressive strength, Rc, is determined. Mechanical tests of three-point bending, and simple compression were performed using a 3R multifunction press with a speed of $0.2 \mathrm{~mm} / \mathrm{min}$ and a maximum load of $250 \mathrm{kN}$. Flexural strength and compressive strength were calculated according to XP P13-901 with equations (1) and (2).

$$
\begin{gathered}
R_{f}=\frac{1,5 \times F_{f} \times l}{b^{3}} \\
R_{c}=\frac{F_{c}}{1600}
\end{gathered}
$$

where:

$\mathrm{R}_{\mathrm{f}}$ - bending strength (MPa), b- the side of the prism square section (mm); $F_{f}$ - the failure load applied in the middle of the prism $(\mathrm{N}), \mathrm{l}$ - distance between supports (mm)

Rc - compressive strength (MPa), Fc - the failure load (N), $1600=40 \times 40 \mathrm{~mm}$ - platens area or auxiliary plates $\left(\mathrm{mm}^{2}\right)$.

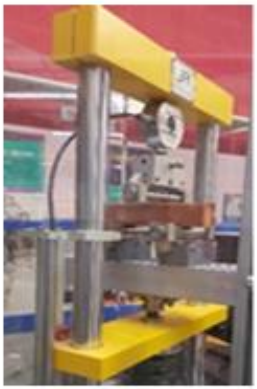

three-point



Compression tests

\section{RESULT AND ANALYSES}

\section{A. Physical property}

The results obtained from dry density and drying shrinkage tests are shown in Table 4 . The density of the reinforced soil specimens decreases with increasing straw content. The density reduction varied between 10 and 13\%. Similar trends have been observed in previous studies [22], [23] of soil blocks / bricks reinforced with other natural fibres. The addition of rice straw to adobe blocks causes the density of the composite to drop due to the low density of these inclusions.

The results reported in also indicate that the linear shrinkage of test pieces with different volume fractions of rice straws decreased with the increase in straw content.

By incorporating coconut and oil palm fibres into adobe blocks, Danso et al [9] have also observed a significant improvement in physical properties.

The addition of the fibres reduces the drying shrinkage of the adobes because these fibres and straws resist the deformation of the soil matrix by friction.

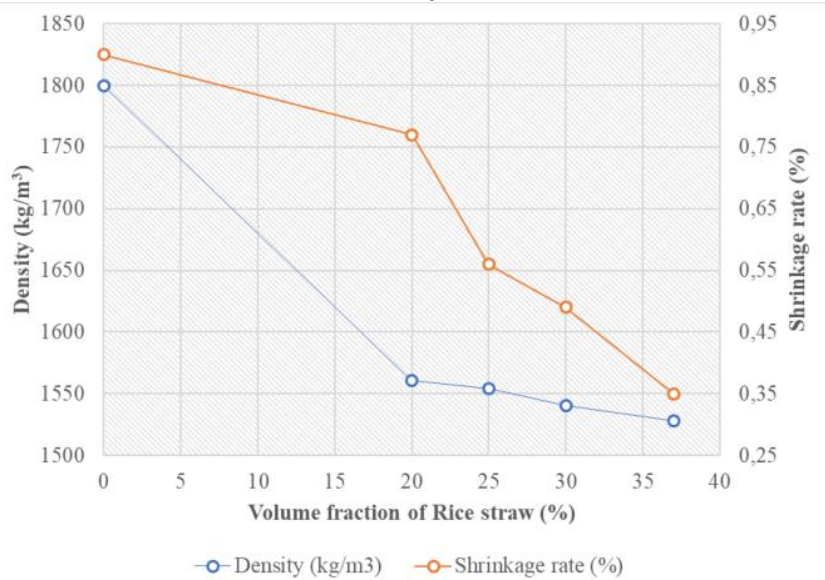

Figure 5: influence of straw proportion on density and drying shrinkage

\section{B. Mechanical properties}

The compressive strength of banco specimens increased with a rice straw fibre content ranging from 20 to $25 \%$ by volume, and then began to decrease, as shown in Figure 6.

This trend is consistent with previous studies who used other fibres or straws in soil blocks where optimal resistance was followed by a subsequent drop in fibre inclusions or straws higher. An inflection point on the variation curve of the compressive strength of the composites is observed at $25 \%$ of rice straw. The optimum increase in compressive strength was $63 \%$ compared to the control sample. This is justified by the good ground-straw adhesion which also prevents the propagation of cracks in the adobe blocks. These fibres form indeed bridges between the cracks and thus contribute to the improvement of the resistance. Conversely, after a critical point [9], resulting in a reduction of cohesion with the soil [46] and a rupture of the clay matrix [24], the clay-straw composite is weakened. It is also likely that the presence of a greater number of pores due to the increase in the straw content in the composite could lead to a reduction of the resistances.

Figure 4: Testing procedures 
The results of the tensile strength tests are shown in Figure 6. Contrary to the compression behaviour, the tensile strength has an evolutionary shape up to $37 \%$ straw in volume of soil.

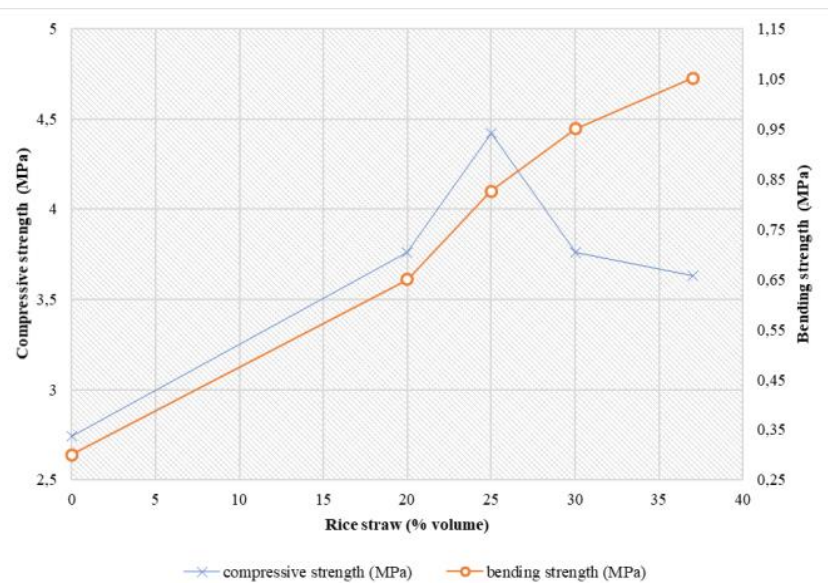

Figure 6: Variation of compressive strength and flexural tensile strength depending of the straw content

In order to determine an optimal rice straw content, a cross analysis of the different experimental results obtained for the mechanical strengths, the density and the rate of shrinkage.

Since the main stress to which adobe is subjected as a construction material is compressive stress, the optimal addition of rice straw in the clay matrix for better compromise mechanical strength, density and shrinkage is 25 $\%$ by volume of soil.

It is noticed during the loading of the adobe specimens with addition of straw to different proportions the progressive appearance of microcracks contrary to the adobe specimens without addition of which the rupture is abrupt (Figure 7). Because of their good tensile strength, the straws oppose the propagation of cracks. This justifies the improvement of the compressive strength of adobes with the addition of rice straws. The presence of straw gives the adobe blocks, initially fragile, a ductile character. Bouhicha et al. [25], Cai et al. [26] and Danso et al. [17] made the same observations with the addition of various natural fibres.

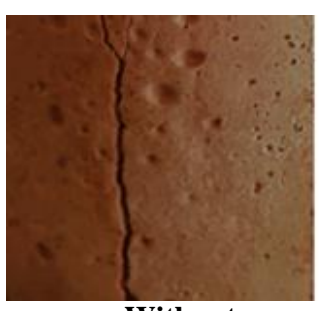

a- Without

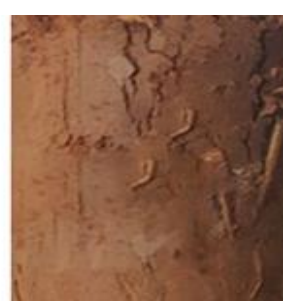

b- with straw
Figure 7: cracking of adobes test pieces

\section{CONCLUSION}

This study shows the influence of rice straw as reinforcing material in the clay matrix through parameters such as density, drying shrinkage and mechanical properties. We then determined the optimal proportion of straw for a compromise between these different parameters.

The results of this experimental study can be summarized as follows:

(1) The saturation of the straw is positive on the earth-straw mixture. It avoids the phenomenon of water absorption in the clay matrix and therefore a too brutal drying.

(2) As the straw content increases, the rate of shrinkage decreases.

(3) Experimental results showed a reduction in density, workability, shrinkage, drying and cracking as the amount of straw increased in the mixture.

(4) The addition of straw to the clay soil usually improves the mechanical performance of the clay.

(5) The good tensile strength of the straws and the strong bond between the soil and the rice straws give the adobe blocks a good ductility in traction.

(6) The flexural strength increases constantly with the addition of straw; which shows that straw brings ductility to the earth. The composite is more resistant to traction.

(7) Reinforced samples with different straw proportions show an increase in compression values at a specific point beyond which they begin to decrease. The compressive strengths have a Gaussian evolution. At 25\% rice straw, there is a point of inflection on the curves of variation of the compressive strength. This gives an idea of the optimal proportion of rice straw to strengthen the soil and increase its value of compressive strength for practical purposes.

(8) To obtain optimal mechanical behaviour of clay soil mixtures and rice straw, a quantity of $25 \%$ by volume of short straws $(40 \mathrm{~mm})$ is recommended.

\section{REFERENCES}

1. H. Niroumand, M. F. M. Zain, et M. Jamil, « Various Applications of Earth Architecture », Procedia - Soc. Behav. Sci., vol. 89, p. 231-236, 2013.

2. F. Pacheco-Torgal et J. A. Labrincha, « The future of construction materials research and the seventh UN Millennium Development Goal: A few insights », Constr. Build. Mater., vol. 40, p. 729-737, 2013.

3. G. Minke, Earth construction handbook : the building material earth in modern architecture. WIT Press, 2000.

4. L. Fontaine, R. Anger, P. Doat, H. Houben, et H. Van Damme, Bâtir en terre: du grain de sable à l'architecture. Belin Paris, 2009.

5. B. Berge, Ecology of Building Materials. Taylor \& Francis, 2009.

6. E. Avrami, H. Guillaud, et M. Hardy, Terra literature review. 2008.

7. H. Binici, O. Aksogan, D. Bakbak, H. Kaplan, et B. Isik, « Sound insulation of fibre reinforced mud brick walls », Constr. Build. Mater., vol. 23, n ${ }^{\circ}$ 2, p. 1035-1041, 2009.

8. V. Sharma, H. K. Vinayak, et B. M. Marwaha, «Enhancing sustainability of rural adobe houses of hills by addition of vernacular fiber reinforcement », Int. J. Sustain. Built Environ., vol. 4, $\mathrm{n}^{\circ}$ 2, p. 348-358, déc. 2015.

9. H. Danso, D. B. Martinson, M. Ali, et J. B. Williams, « Physical mechanical and durability properties of soil building blocks reinforced with natural fibres », Constr. Build. Mater., vol. 101, p. 797-809, 2015.

10. B. Taallah, A. Guettala, S. Guettala, et A. Kriker, « Mechanical properties and hygroscopicity behavior of compressed earth block filled by date palm fibers », Constr. Build. Mater., vol. 59, p. 161-168, mai 2014.

11. Y. Millogo, J. C. Morel, J. E. Aubert, et K. Ghavami, « Experimental analysis of Pressed Adobe Blocks reinforced with Hibiscus cannabinus fibers », Constr. Build. Mater., vol. 52, p. 71-78, févr. 2014.

12. J. E. AUBERT, «Caractérisation des briques de terre crue de MidiPyrénées,» ", Institut National des sciences Appliquées-Université Paul SABATIER Toulouse III, Toulouse, 2013.

13. R. Alavéz-Ramírez, P. Montes-García, J. Martínez-Reyes, D. C Altamirano-Juárez, et Y. Gochi-Ponce, « The use of sugarcane bagasse ash and lime to improve the durability and mechanical properties of compacted soil blocks », Constr. Build. Mater., vol. 34, p. 296-305, sept. 2012. 
14. M. A. Bahobail, "The Mud Additives and their Effect on Thermal Conductivity of Adobe Bricks », J. Eng. Sci. Assiut Univ., vol. 40, ${ }^{\circ} 1$, p. 21-34, 2012.

15. E. Quagliarini et S. Lenci, «The influence of natural stabilizers and natural fibres on the mechanical properties of ancient \{Roman \} adobe bricks », J. Cult. Herit., vol. 11, nº 3, p. 309-314, juill. 2010.

16. C. Labintan, R. Benelmir, M. Gibigaye, et A. Donnot, "Characterization of the "Banco", a Building Material for a Tropical and Rural Environment », Int. J. Energy, Environ. Econ., vol. 23, $\mathrm{n}^{\circ} 2$, p. 203, 2015.

17. H. Danso, B. Martinson, M. Ali, et C. Mant, «Performance characteristics of enhanced soil blocks: a quantitative review », Build. Res. Inf., vol. 43, n 2, p. 253-262, mars 2015.

18. V. Sharma, H. K. Vinayak, et B. M. Marwaha, «Enhancing compressive strength of soil using natural fibers ", Constr. Build. Mater., vol. 93, p. 943-949, sept. 2015.

19. D. M. C. (Andres) et D. L. Manea, «Innovative Building Materials Using Agricultural Waste », Procedia Technol., vol. 19, p. 456-462, 2015.

20. Y. K. Wu, Y. B. Li, et B. Niu, « Investigation of mechanical properties of randomly distributed sisal fibre reinforced soil », Mater. Res. Innov., vol. 18, no sup2, p. S2-953-S2-959, mai 2014.

21. A. Guettala, A. Abibsi, et H. Houari, « Durability study of stabilized earth concrete under both laboratory and climatic conditions exposure », Constr. Build. Mater., vol. 20, nº 3, p. 119-127, avr. 2006.

22. I. Soto Izquierdo, O. Soto Izquierdo, M. A. Ramalho, et A. Taliercio, «Sisal fiber reinforced hollow concrete blocks for structural applications: Testing and modeling », Constr. Build. Mater., vol. 151, p. $98-112,2017$

23. H. Danso, D. B. Martinson, M. Ali, et J. Williams, « Effect of fibre aspect ratio on mechanical properties of soil building blocks », Constr. Build. Mater., vol. 83, p. 314-319, mai 2015.

24. A. Laborel-Préneron, J. E. Aubert, C. Magniont, C. Tribout, et A. Bertron, " Plant aggregates and fibers in earth construction materials: A review », Constr. Build. Mater., vol. 111, p. 719-734, mai 2016.

25. M. Bouhicha, F. Aouissi, et S. Kenai, « Performance of composite soil reinforced with barley straw », Cem. Concr. Compos., vol. 27, $n^{0} 5$, p. 617-621, mai 2005.

26. Y. Cai, B. Shi, C. W. W. Ng, et C. Tang, « Effect of polypropylene fibre and lime admixture on engineering properties of clayey soil », Eng. Geol., vol. 87, $n^{\circ} 3$, p. 230-240, nov. 2006

\section{AUTHORS PROFILE}

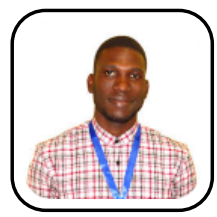

LABINTAN Adéoumi Clément, Researcher, Laboratory of Energetics and Applied Mechanics, University of Abomey-Calavi, Cotonou, Benin.



ADADJA Christian Enagnon, Researcher, Laboratory of Microstructure Studies and Mechanics of Materials, University of Lorraine, Metz, France.

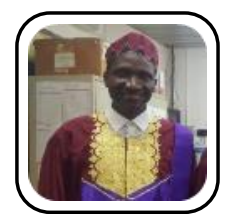

GIBIGAYE Mohamed, Professor, Laboratory of Energetics and Applied Mechanics, University of Abomey-Calavi, Cotonou, Benin

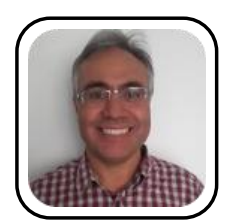

ZAHROUNI Hamid, Professor, Laboratory of Microstructure Studies and Mechanics of Materials, University of Lorraine, Metz, France.

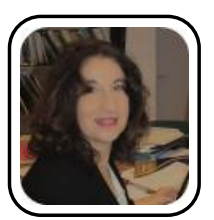

HATTAB Mahdia, Professor, Laboratory of Microstructure Studies and Mechanics of Materials, University of Lorraine, Metz, France. 